\title{
ORLAS DA MEMÓRIA: A LEMBRANÇA FUTURA DE Antônio Salles na obra de Pedro Nava
}

EDGES OF MEMORY: THE FUTURE REMEMBRANCE OF Antonio Salles in Pedro Nava's work

Maria Alice Ribeiro Gabriel

Universidade de São Paulo

São Paulo - SP

\section{Resumo}

O retrato biográfico do jornalista, poeta e romancista Antônio Salles (1868-1940) na obra de Pedro Nava (1903-1984) é notável, verdadeiramente afetuoso. A partir da morte do pai de Nava, em 1911, essa ligação paternal com seu tio acentuar-se-á nos próximos anos. O casal Antônio e Alice Nava Salles não possuía filhos e assim tiveram uma influência privilegiada sobre a infância e juventude de Nava, estreitamente associada a algumas das mais belas recordaçóes dos primeiros volumes das memórias do médico. Segundo Nava, o exemplo de Salles como homem de letras foi determinante quanto à evolução de sua carreira de escritor. Apesar de seu evidente valor artístico e histórico, a escrita memorialística de Nava é um tema pouco discutido na literatura brasileira do século XXI. Este estudo é uma leitura comparativa de fragmentos dessas memórias e das informaçôes biográficas provenientes do arquivo pessoal de Antônio Salles, testamento intelectual transmitido a seu sobrinho Nava.

Palavras-chave: Antônio Salles, Pedro Nava, memorial, patrimônio imaterial.

\section{Abstract}

The biographical portrait of the journalist, poet and romancist Antônio Salles (18681940) in Pedro Nava's work (19031984) is noteworthy and remarkably fond. Since the death of Nava's father in 1911, this bond with his paternal uncle continued to grow throughout the years. The married couple Antônio and Alice Nava Salles did not have children and so, they had a significant influence on Nava's childhood and youth, which is evidenced in some of the most beautiful recollections in the first volumes of the doctor's memoirs. According to Nava, the example set by Salles as a man of letters was decisive in the evolution of his career

\section{Résumé}

Le portrait biographique de le journaliste, poète et romanciste Antonio Salles (18681940) dans l'oeuvre de Pedro Nava (1903-1984) est remarquable, vraiment affectueux. À partir de la mort du pére de Nava, en 1911, cette liaison avec son oncle paternel va s'accentuer dans les années a venir. Le couple Antônio et Alice Nava Salles n'avait pas d'enfants. Ainsi, ils ont eu influence privilegiée sur l'enfance et jeunesse de Nava, étroitement associée à certains de leurs plus beaux souvenirs des premiers volumes de las mémoires du médicin. Selon Nava, l'exemple de Salles comme homme de lettres a été déterminant quant à l'évolution de 
as a writer. Despite their evident artistic and historical value, Nava's vast memoirs are still a theme that has not been widely discussed in Brazilian literature of the 21 st century. This study is a comparative reading of fragments of Nava's memoirs and biographical information obtained from Antonio Salles's personal archive, an intellectual legacy bequeathed to his nephew Nava.

Keywords: Antônio Salles, Pedro Nava, memorial, intangible heritage. sa carrière d'écrivain. En dépit de son valeur artistique et historique évident, l'écriture mémorialiste de Nava est un thème peu discuté dans la littérature brésilienne du XXIe siècle. Cette étude est une lecture comparative de fragments de ces mémoires et des informations biographiques provenants du archive personelle de Antonio Salles, testament intellectuelle transmis à son neveu Nava.

Mots-clés: Antonio Salles, Pedro Nava, mémorial, patrimoine immatériel.

\section{A man's real life is that accorded to him in the thoughts of other men by reason of respect or natural love. \\ (Joseph Conrad, Under Western Yes)}

Quais os caminhos para se relatar o passado e perscrutar suas expressóes de ressonância manifestas no presente? Entre os grandes temas da contemporaneidade, o termo memória associou-se à ideia de que textos culturais de épocas pregressas lançassem alguma luz sobre a complexidade do presente. Nesse sentido, Judith Schlanger assinalou, em La mémoire des oeuvres (1992) e Présence des oeuvres perdues (2010), o fato de patrimônios culturais de todas as ordens desaparecerem por fatores históricos e naturais, mas sobretudo por abandono e falta de conservação. Desse modo, esculturas, pinturas, monumentos, documentos, fotografias, manuscritos e textos literários perdurariam unicamente de maneira dispersa e fragmentária, citados, reproduzidos e recriados em outras obras pelo trabalho da imaginação e da memória.

$\mathrm{O}$ ato mnemônico na criação literária e o apreço à pesquisa histórica são questóes específicas da memorialística de Pedro Nava. A crônica histórica e literária articulam-se na descrição de perfis humanos, cenas e paisagens extintas, muitas vezes afirmando veemente repúdio perante "atos atentatórios ao nosso patrimônio histórico e artístico" (NAVA, 1974: 159). Assim, ao transcrever o passado, a "imaginação dá colorido" ao derradeiro retrato que ficou do Visconde de Jaguaribe (NAVA, 1974: 173) e à "majestosa construção começada a levantar em 1745 pelo brigadeiro Alpoim e inaugurada em 1750, com a presença de Gomes Freire de Andrade, para abrigar o primeiro convento de religiosas que existiu no Brasil” (NAVA, 1974: 159), demolido 
em 1911. A partir da litografia de 1865, de Pieter Godfried Bertichen, Nava reproduziu o plano arquitetônico e parte do cotidiano do Convento da Ajuda, localizado no Rio de Janeiro.

O autor é criterioso e criativo ao reconstituir o passado, utilizando e expandindo fontes tradicionais do historiador. Cartas, documentos, fotografias, objetos pessoais e testemunhos combinam-se à evocação de obras literárias e elementos da tradiçấo oral: adágios, cançôes e contos populares. Fantasia e imaginação increvem-se poeticamente em digressóes sobre o significado de acontecimentos e a importância de determinadas pessoas em suas memórias - como sucede em Baú de ossos (1972), quando passagens da infância são narradas integrando fatos, lugares e conhecidos ao contos maravilhosos.

Entrevistado por Edmilson Caminha, em 1984, Nava ponderou sobre a reaçáo dos "que se sentiram tocados de uma maneira extraordinária" pela menção de alguns familiares em suas memórias: "O retrato não poderia ser favorável” (CAMINHA; 1995: 40). Por esse ângulo, em específico, Nava afirma o primado da autoridade subjetiva da memória sobre a linearidade cronológica e imparcialidade ideal do narrador biográfico:

Eu tenho de escrever o que eu quero escrever - fazer a interpretação à minha maneira, sem compromisso com coisa alguma, inclusive com a verdade pura e simples do relatório. Eu náo tenho compromisso com essa verdade: meu compromisso é com a verdade passando um pouco para o terreno do verossímil, da verossimilhança, que essa é mais interessante, porque interpretativa. Acho que o memorialista é um narrador de fatos, um contador de coisas passadas; mas, pela interpretação que pode fazer do tempo, ele entra um pouco na ficção, não na de invenção, mas na de contar o verossímil, o possível (CAMINHA, 1995: 42).

Fernando Durán López (1996: 28) distinguiu na autobiografia política uma retórica característica, "todo um conjunto de princípios que estructuran el discurso memorialístico con la intención de hacerlo más persuasivo, una técnica de la argumentación y la narración" que, sem se tornar aqui síntese normativa e generalizante, aproxima-se da verossimilhança "interpretativa" do narrador naveano: "Cada elemento de la narración, cada recurso formal, cada palabra, está encaminada a convencer, a crear ilusión de verosimilitud y, más todavia, de veracidad" (LÓPEZ, 1996: 44). Enquanto rétor, o memorialista pode atualizar ou mudar o sentido de algo pelo enfoque sugerido.

Yosef Hayim Yerushalmi notou que, em certas ocasióes históricas, as pessoas retomariam o passado distante para recuperar elementos esquecidos ou negligenciados, capazes de estabelecer no presente inesperada vibração simpatizante, um senso de empatia, de reconhecimento (YERUSHALMI, apud COHEN, 2014: 27) - pensamento congênere ao de Schlanger sobre a memória cultural e literária de obras "esquecidas". 
Por "senso de empatia", Antônio Salles encontra, na prosa de Nava, primorosa obra de arte para ser recordado, notadamente em Baláo cativo (1973), que narra a história da "gente inamolgável do panfletário, polemista, jornalista, crítico, ensaísta romancista e poeta Antônio Salles", reiterando: "Porque verdadeiro e único é o homem magnânimo que tive como amigo antes de ter noção de amizade" (NAVA, 1973: 229).

Este estudo propóe breve reflexão sobre o memorial dedicado a Antônio Salles na prosa autobiográfica de Nava, com base em apontamentos do Inventário do Arquivo Antônio Sales ${ }^{1}$ (2007), legado de documentos pessoais e familiares do escritor cearense. Os comentários e a teorização apoiam-se nas obras de Jacques Le Goff (1996), Peter Homans (2000) e Paul Cohen (2014) sobre as implicações da história e da memória nas esferas pública e privada, assinalando os processos de construção da memória subjetiva.

Inclinada ao ensaio histórico, a narração subjetiva relaciona a memorialística à historiografia. $\mathrm{O}$ historiador firma-se na documentação oficial de caráter probatório da memória. Nava permeia a citação de documentos com o relato oral, reservando espaço às fontes eruditas, ao anedotário familiar, com "suas frases de sabedoria gregária" e à cultura popular, como a "história do João Jiló" ou dos "dois compadres de Paracatu".

O memorialista confere, no presente, unidade significativa particular à fonte escrita, iconográfica e oral. Convém notar a diligência do Dr. João Marinho, de quem Nava guardou a impressão "do bom gosto com que ele reunira sua biblioteca de clássicos da Medicina e de clássicos portugueses, da prodigiosa memória de que ele era dotado e de sua capacidade de ditar em ordem escrita as suas lembranças" (NAVA, 1974: 375, ênfase do autor). O médico não consentiu ao memorialista "tomar notas do que dizia, com medo de falseamento da verdade", exigindo que "escrevesse sob ditado".

Quanto às fontes, Le Goff declarou a coexistência dos aspectos materiais e imateriais da cultura perante a historiografia de um modo que os especifica e canoniza:

[...] desde a Antiguidade, a ciência histórica, reunindo documentos escritos e fazendo deles testemunhos, superou o limite do meio século ou do século abrangido pelos historiadores que dele foram testemunhas oculares e auriculares. Ela ultrapassou também as limitaçóes impostas pela transmissão oral do passado. A constituiçáo de bibliotecas e de arquivos forneceu assim os materiais da história. Foram elaborados métodos de crítica científica, conferindo à história um dos seus aspectos de ciência em sentido técnico [...]. Portanto, não se tem história sem erudição. Mas do mesmo modo que

\footnotetext{
${ }^{1}$ Conforme Eliane Vasconcellos (2007: 15), "Nava sempre respeitou a grafia original do sobrenome do tio afim", portanto, neste estudo, exceto pelas citaçóes referentes a outros autores, convencionou-se manter a grafia adotada pelo memorialista em suas obras Baú de ossos, Balâo cativo e Chão de ferro.
} 
se fez no século XX a crítica da noção de fato histórico, que não é um objeto dado e acabado, pois resulta da construção do historiador, também se faz hoje a crítica da noção de documento, que não é um material bruto, objetivo e inocente, mas que exprime o poder da sociedade do passado sobre a memória e o futuro: o documento é monumento. Ao mesmo tempo ampliou-se a área dos documentos, que a história tradicional reduzia aos textos e aos produtos da arqueologia, de uma arqueologia muitas vezes separada da história. Hoje os documentos chegam a abranger a palavra, o gesto. Constituem-se arquivos orais; são coletados etnotextos (LE GOFF, 1996: 9-10, ênfase do autor).

A expansão "da área dos documentos" aprimorou as noçóes de arquivo e testemunho, antes centrado na palavra escrita. Após a Segunda Guerra, intensificaram-se os estudos sobre a função de renovação cultural da memória. Nesse domínio, Peter Homans e Paul Cohen analisaram o significado de imagens e símbolos culturais presentes na memória individual e coletiva de sociedades contemporâneas. Observe-se que, no processo de registro arquivístico, Nava cultivou a iconografia em suas anotaçóes de médico e memorialista (VASCONCELOS, 2001: 26). Em Baú de ossos, ele recordou o aspecto material e imaterial do primeiro caderno de desenhos, usado de 1910 a 1918:

Presente de tio Salles que fora comprá-lo comigo à Rua Haddock Lobo [...] Foi folheado por dezenas de mãos agora mortas, cujo suor vivo e cujas impressóes digitais deixaram nele - para sempre! - seu traço. É desses objetos mágicos, embebidos de gente - gente falecida - cujo resto material é sentido pelos cães que uivam aos mortos ou pelos bruxos que os invocam. Esse caderno lembra sobretudo meu período de realeza em Aristides Lobo 106. Eu, sentado à escrivaninha de tio Salles, desenhando e enchendo de admiração meus pais e a roda deslumbrada das tias e tios (NAVA, 1974: 353-354).

No excerto, o impulso de resistir à melancolia ao visualizar o passado não prevalece. Homans discorreu sobre situaçóes que colapsariam referenciais simbólicos da sociedade, demandando uma necessária ressignificação em reparo à coesão e equilíbrio perdidos. Ao prefaciar Symbolic Loss (2000), ele destacou as contribuições de Saul Friedländer, Geoffrey Hartman, William Langer e James E. Young sobre a correlação entre memória e testemunho na literatura e na história para essa restauração simbólica.

Ao adotar o termo "memória" em lugar de "história", uma vertente da tradição francesa estudiosa do Holocausto aproximou os campos da história e do fenômeno do luto. A memória estaria mais perto da investigação do luto que a história e franqueável à antropologia e psicologia, disciplinas acessíveis à abordagem do luto. Mais próxima da experiência imediata que a história, a memória constituiria uma experiência de aproximação, e a história, de 
distanciamento, o que ampliaria a percepçáo científica de contextos históricos específicos, sem incorrer nas faltas e desvios de interpretação atribuídos à psicobiografia e psico-história (HOMANS, 2000: 31-32, ênfase do autor).

Paul Cohen discutiu a aproximação entre o produto das ideaçóes da memória popular e a realidade histórica em History and Popular Memory: The Power of Story in Moments of Crisis (2014). A canção folclórica, o conto, a crônica oral épica, a legenda, o mito, o hino, a oração e a poesia encomiástica constam das manifestaçóes absorvidas pelo relato e o testemunho, na qualidade de fontes literária e historiográfica. Com variantes e temáticas centradas em épocas de crise, as produçóes populares forneceriam significados de orientação ideológica, mítica ou nacionalista, transcrevendo-os em narrativas coerentes (COHEN, 2014: 10-11). Análogos ao acervo da cultura popular,

[...] los archivos privados forman parte del patrimonio documental universal, siendo um complemento de los archivos públicos, y su interés e importancia transciende más allá de ámbito familiar. Es necesaria la conservación y preservación de estos archivos por la utilidad que tienen para la investigación histórica (NICOLÁS; GARCÍA, 1994: 121).

O arquivo pessoal de Salles foi doado por Nava em janeiro de 1983, ano anterior à morte do memorialista. $\mathrm{O}$ acervo consta no total de 1.809 documentos impressos e manuscritos, correspondente ao período de 18 de agosto de 1810 a 4 de julho de 1965, e pertence atualmente à Fundaçáo Casa de Rui Barbosa, localizada na cidade do Rio de Janeiro, integrando o Arquivo-Museu de Literatura Brasileira. Em prefácio ao Inventário do Arquivo Antônio Sales, Eliane Vasconcellos define arquivo privado, segundo o Manual de arranjo e descrição de arquivos, diferenciando-o do arquivo familiar, condiçáo da documentação herdada por Nava. "No que diz respeito ao acesso e à utilização dos dados do arquivo, cabe aos herdeiros autorizálos, porque a legislação dá plenos poderes ao detentor dos direitos autorais" (VASCONCELLOS, 2007: 9-10).

Com o passar do tempo, a vida familiar transmite à vida social testemunhos de relaçóes pessoais, econômicas, culturais e políticas. Para Olga Gallego Dominguez (apud NICOLÁS; GARCÍA, 1994: 121), o arquivo privado emana de indivíduos e pessoas jurídicas privadas (famílias, associações, fundaçóes, igrejas etc.); já o arquivo familiar é gerado pelas atividades da pessoa em vida, ou dos familiares através de gerações, constituindo, usualmente, a etapa final da integraçáo de outras famílias ou do desmembramento dos componentes que imprimiram algum vestígio nesse espólio.

Horacio Tarcus expôs, em "Archivos, bibliotecas y la memoria obrera, social y cultural de los argentinos” (2015), a situação arquivística e 
biblioteconômica do país, reclamando a dispersão de arquivos e bibliotecas privadas mediante o desinteresse ambiente em sua conservação ou venda fracionada a sebos. Consequentemente, grande parte do patrimônio histórico nacional subsiste, mas custodiado sob a forma de patrimônio familiar, quando a cessão deste ao espaço público permanece inexequível.

Ilustrativa é a carta de Ana de Serpa, de 30 de setembro de 1923, relatando o pesar pela morte do marido, Justiniano de Serpa, em agosto daquele ano, pedindo a intervenção de Salles "junto ao Estado para que este compre a biblioteca do finado, a fim de ajudá-la materialmente" (VASCONCELOS, 2007: 84). Já a biblioteca de Nava foi vendida à Universidade de Brasília. Alguns livros doados ao Arquivo-Museu de Literatura Brasileira passaram à Fundação Casa de Rui Barbosa (VASCONCELOS, 2001: 10). Sobre a doação do arquivo pessoal de Salles, Nava escreveria a Sânzio de Azevedo, entre 9 e 10 de maio de 1984, portanto, 3 ou 4 dias antes de deixar "seus amigos e admiradores imersos em dor e perplexidade..." (AZEVEDO, 2007: 26):

Devo uma explicação a V. sobre minha resolução de doar esta correspondência à Casa de Rui. Fiz bem porque estas cartas em número de mais de 1.000 estão todas classificadas por índices cruzados de pessoa e assunto e sua consulta é extremamente facilitada pelo cuidado e o carinho que o Prof. Galante de Sousa pôs na sua classificaçáo. Entreguei-as ao Plínio [Doyle] porque assim, enquanto eu estiver vivo, estarão sob minhas vistas. Tenho por todo o arquivo de meu tio o maior carinho pelo que ele representava de preocupaçóes para minha incomparável tia Alice Nava Sales (AZEVEDO, 2007: 26).

Ronald D. Lambert (apud MEETHAN, 2008: 101) destacou a história familiar enquanto modalidade memorialística capaz de redescobrir ligaçóes, identificar, arranjar e catalogar o passado, oferecendo à pesquisa histórica a conexão perdida entre a história familiar e pessoal. Machado de Assis, cultor das memórias como gênero literário, indicou tal "conexão perdida" em Esaú e Jacó (1904): "Em vez de achar quase extinta a influência [...], vinha dar com ela feita consolação da ausência, tão viva que bastava a memória, sem presença dos modelos" (ASSIS, 1994, 116). Em Baú de ossos, Nava reconstitui a "presença dos modelos" do pai, José Pedro da Silva Nava, em 1893:

Era o ano da bomba de Vaillant na Câmara Francesa, da Revolta da Armada contra Floriano e aquele em que outra influência intelectual ia-se fazer efetiva junto de meu Pai, pelo casamento de sua irmá mais velha Cândida (Candoca), com Júlio Augusto de Luna Freire. Homem de grande cultura, ledor incansável, informado de todas as literaturas, sua influência de letrado maduro deve ter sido muito grande sobre o espírito de meu Pai, e quase tão importante como a que exerceu Antônio Salles, também tornado cunhado, por seu casamento, a 16 de junho de 1894, com minha tia Alice (Yâim). Tio Salles, quando 
entrou na família, já vinha consagrado, pela publicação, em 1890 dos seus Versos Diversos (NAVA, 1974: 84).

Assim, desde o início, a presença de Salles conecta-se à história da família de Nava de forma muito específica, pelos laços de amizade e pela identificação intelectual:

Eu não posso me lembrar senão de caso ou outro, das conversas de minha família, tais os referidos anteriormente. Se não recordo detalhes, fixei o espírito e a essência do que se dizia, principalmente do que se não dizia... [...] A conversa geral era cheia de preferências pelas idéias, pelas coisas e causas nobres, pelos assuntos intelectuais - estes, versados simplesmente, como moeda de todo dia. Nenhum desses grandes ledores que eram meu Pai, tio Salles, tio Júlio, minhas tias Alice e Candoca se permitiam pedantismo ou brilho. [...] Tenho visto noutros, mas jamais ultrapassada, aquela distinçáo moral e intelectual que eram as tônicas do grupo familiar dentro do qual acordei para a vida e que davam à nossa gente (coincidentemente naquele tempo e naquele espaço) a consciência de um lugar certo, adequado e devido na sociedade da época - onde eram úteis - como peças de máquinas - seus funcionários, comerciantes, médicos, notários, bacharéis formados, membros da nossa intelligentsia - para cujo nivel seria tăo extravagante ser bicheiro como ser eleito deputado. Ninguém tinha alma de parvenu (NAVA, 1974: 350).

Trovas do Norte (1895), publicado após Versos Diversos, foi motivo de "um duelo em prosa ou em verso" (ALBUQUERQUE, 2000: 47) proposto por Adolfo Caminha a Salles - algo que não impediu o convite à Caminha para "fundar com ele e outros a Padaria Espiritual" (BEZERRA, 2009: 304). A polêmica estendeu-se de 10 a 22 de abril de 1891, Salles manifestando-se pelo Libertador e Caminha "pelas colunas de O Estado do Ceara" (VASCONCELOS, 2007: 28). Dolor Barreira registrou "a renhida polémica" com pormenores em História da literatura cearense (1986: 332). Já a história da agremiação, fundada em 1892 e extinta em 1898, está em Baú de ossos:

Padaria Espiritual foi o nome dado por Antônio Salles a uma sociedade cearense de letras, cujo aspecto irreverente, revolucionário e iconoclasta só encontra símile no movimento que sairia, trinta anos depois, da Semana de Arte Moderna. Adolfo Caminha, rememorando como ela surgiu, passa um pouco por cima da figura de Antônio Salles e escamoteia seu papel de principal fundador e animador daquele grupo de intelectuais. Não pensam assim Jorge Brandão Maia, Leonardo Mota, Dolor Barreira e Herman Lima - que muito justamente dão a César o que é de César e a Salles o que é de Salles. O nome foi achado por ele. Foi ele o autor de seu programa (NAVA, 1974: 85-6). Salles presidiu a primeira sessão "e só não continuou no cargo porque 
fez questão de passá-lo a Jovino Guedes" (NAVA, 1974: 86). Os intelectuais reuniam-se diariamente no Café Java, à Praça do Ferreira. O programa de instalação preconizava:

I - Fica organizada nesta cidade da Fortaleza, capital da Terra da Luz, antigo Siará Grande, uma sociedade de rapazes de Letras e Artes denominada Padaria Espiritual, cujo fim é fornecer pão de espírito aos sócios em particular e aos povos em geral.

II - A Padaria Espiritual se comporá de um Padeiro-mor (presidente), de dois Forneiros (secretários), de um Gaveta (tesoureiro), de um Guardalivros, na acepção intrínseca da palavra (bibliotecário), de um Investigador das Cousas e das Gentes, que se chamará - Olho da Providência, e demais Amassadores (sócios). Todos os sócios terão a denominação geral de - Padeiros (VASCONCELLOS, 2007: 11).

Nava nomeou os integrantes a partir de Lopes Filho, Ulisses Bezerra, Sabino Batista, Álvaro Martins, Temístocles Machado e Tibúrcio de Freitas, seguidos de Manuel Pereira dos Santos, proprietário do café, "o mais entusiasta dos animadores da Padaria Espiritual e o Mecenas rústico de seus padeiros" e Joaquim Vitoriano, "que não lia mas ouvia, que não tinha predicados intelectuais [...] leão de chácara" de "punho de bronze", "bengala sibilante" e "peixeira acerada" (NAVA, 1974: 86, ênfase do autor). A primeira sede "instalou-se publicamente, com o maior estardalhaço [...] à Rua Formosa, 105, no dia 30 de maio de 1892”, relatou Nava (1974: 86), tendo por presidentes:

Jovino Guedes, da segunda reunião até 5 de outubro de 1894; a José Carlos da Costa Ribeiro Junior, dessa data até a de sua morte, ocorrida a 29 de maio de 1896; e a Rodolfo Teófilo, de 19 de julho do mesmo ano até 20 de dezembro de 1898 - dia de sua última sessão (NAVA, 1974: 87).

O estandarte da associação foi entregue pela família de Rodolfo Teófilo a Salles, que o confiou ao Arquivo Público do Ceará, a 12 de novembro de 1932:

Era um campo de goles e trazia como insígnias uma caneta plumada cruzada com uma espiga de trigo. De um lado um $P$ e do outro um $E$. Por baixo, a divisa 'Amor e Trabalho' [...] a espiga de trigo termina, em baixo, como pena de escrever. E Padaria Espiritual vem escrito por extenso (NAVA, 1974: 87).

Salles e Teófilo corresponderam-se de 18 junho de 1906 a 2 de outubro de 1930. As cartas de Teófilo versam sobre muitos temas, da política cearense ao envio de sua coleção de livros a Salles, com a segunda edição de Os brilhantes (1895) - e revelaçóes: 
[...] sobre seus problemas pessoais e de saúde. Envio de recortes de jornais. Comentário sobre a ingratidão de Cruz Filho e Sales Campos para com Antônio Salles. Pesar de que os versos de Pierre d'Aratanha, publicados na Gazeta de Notícias, mostrem o começo de um "desequilíbrio mental" (VASCONCELOS, 2007: 87).

Fonte de pesquisa ainda inexplorada seriam as cartas de Manuel Sabino Batista, um dos fundadores da Academia Cearense, com informes sobre a vida literária e política daquela época. Outros nomes poderiam corroborar esta ideia, segundo observou Nava:

Nem todos os padeiros acompanharam a Padaria do princípio ao fim de sua curta vida. Suas fileiras foram desfalcadas pela "indesejada das gentes", que cedo levou Artur Teófilo, José Carlos, Lívio Barreto, Lopes Filho, Sabino Batista e Xavier de Castro. Pela dispersão, que tirou da província Antônio Salles, José Nava e Roberto de Alencar. E pior. Pela incapacidade que têm os homens de se reunirem sem que logo os separe a malquerença, a inimizade, o ódio, o ciúme, a inveja e o despeito (NAVA, 1974: 88).

Sânzio de Azevedo (2015: 17) esclareceu alguns dos "nomes de guerra" dos Padeiros-mores. Salles era Moacir Jurema, em alusão ao romance de José de Alencar, Moacir é o "filho da dor" e "Jurema" "“ju” - espinho e "rema" cheiro desagradável) designava a poçáo misteriosa do sonho, guardada por Iracema. Teófilo era Marcos Serrano. Marcos por chamar-se Rodolfo Marcos Teófilo; Serrano recorda a Serra de Maranguape, terra de sua infância. Sabino Batista adotaria o nome de Sátiro Alegrete.

A singular descrição de Teófilo remonta à viagem de Nava (1976: 224-5) ao Norte, em 1919: "Era um velho mumificado, olhos extremamente doces, sempre calças sungadas e sem vinco, desarrumado, apesar de muito limpo. [...] Esse santo admirável ia nos seus sessenta e cinco para sessenta e seis anos" na época e frequentava a casa de Ana Cândida Pamplona Nava Feijó, "Dona Nanoca”, avó paterna de Nava (1976: 224): "Ia para o escritório de tio Sales e logo começava a falar mal do governo municipal, estadual e federal." A imagem de Chão de ferro (1976) não é única: em Balão cativo, o "Rodolfo que juntava o proselitismo político à hospitalidade recebe Antônio Salles em sua casa" (NAVA, 1973: 223), comparado antes, a Leon Tostói, em Baú de ossos.

No início do século XX, "a inspiração carismática de Rodolfo Teófilo" livraria o Ceará da varíola até meados de 1913, quando a enfermidade recrudesceu (BARBOSA, 1994 apud SANTOS, 2004: 289). Luiz Antonio de Castro Santos notou que Teófilo realizou a vacinação "em regióes controladas por uma oligarquia que lhe era hostil". Lira Neto descreveu as condiçóes dessa "quixotesca" campanha antivariólica em $O$ Poder e a Peste: A Vida de 
Rodolfo Teófilo (1999). Tornada obrigatória a vacinaçáo, em 1904, a iniciativa individual do farmacêutico baiano foi dispensada. As recordaçóes de Nava sugerem as condições em que Teófilo mantinha certa assistência à população:

Não tenho documentos sobre todos os seus componentes, mas dois deles servem de amostra e índice dos outros. Rodolfo Teófilo com aquele seu humanitarismo romântico que, no caso da vacinaçấo contra a varíola lhe valeu as represálias de um governo estúpido, na realidade, segundo Isaac Amaral, exercia uma sorte de tolstoísmo em que ele e a mulher se despojavam para repartirem tudo - roupa, comida, remédio, dinheiro, conselho. [...] Lembro-me ainda de uma visita que fiz, em 1919, à casa desse amigo do povo. Lembro-me da pobreza do seu lar - pobreza que era resplandecente e alegre porque não era a da perda, do desgaste, da destruição, mas a da proximidade da vida estritamente natural. Quanto a Antônio Salles, esse já veio para a Padaria com uma tradição de rebelde (NAVA, 1974: 97).

Contida na história de Nava, a biografia de Salles apresenta relação especular com a narrativa de episódios marcantes da infância e juventude do memorialista, mas sua influência intelectual não se enraizaria sem o afeto e a confiança que a precederam:

A primeira biblioteca que tive em minhas máos foi a do meu tio Antônio Sales, quando vim morar com ele aqui no Rio. Foi ele quem me iniciou, eu li uma porção de coisas [,,,]. O pessoal da "Padaria Espiritual”, por exemplo. Conheço quase toda a obra de Rodolfo Teófilo, inclusive os seus romances. Tudo isso eu li na biblioteca do Sales. E certos autores com quem ele privava, como Machado de Assis, que ele tinha como mestre. Li alguma coisa do Machado, que na época não me atraiu como viria a atrair depois, na idade madura. Gostei do Lima Barreto à primeira vista, foi o Sales quem me apresentou a ele. [...] Li também os ingleses, meu tio gostava muito da literatura inglesa. Quando saíamos juntos era fatal uma visita ao Garnier e ao Crashley, uma casa que vendia coisas da Inglaterra, desde comida, artigos de esporte, de toalete, até livros. Todos esses autores tiveram muita influência sobre mim (CAMINHA, 1995: 47).

As primeiras observaçóes da realidade com olhos de esteta e as recordaçôes do "exemplo, que devia ser permanente, da vida de Antônio Salles” (NAVA, 1973: 358), encontram-se, principalmente, em Baú de ossos, Balão cativo e Chão de ferro:

Meu tio Antônio Salles, que se comprazia tanto com a companhia de crianças como com a de adultos, era o amigo adorado pelos sobrinhos. Entre eles, ele me preferia e é por isso que eu saía frequentemente com ele. Aos passeios que fizemos juntos, devo aquisiçóes progressivas nos limites de minha geografia 
urbana que estendi a Santa Teresa, ao Flamengo, a Botafogo e à Copacabana das pitangueiras [...] $\mathrm{Na}$ medida em que se olhava a paisagem, via-se que suas cores vinham se encorpando e tomando tonalidades mais vivas com a aproximação. À direita e à esquerda eram os verdes violentos e profundos da mata; o aço das rochas descobertas e lisas; o terra-de-sena, o cobre e o gris de barrancos cortados; a policromia dura das encostas cheias de casas, de faiscaçóes de vidraça e chispas de claraboia. Tudo se diluía gradualmente e os planos longínquos se esbatiam - irreais na luz azul-clara, nos róseos de pétala e na fina poeira dourada. Cedo aprendi a perceber esse contraste tão vivamente apanhado nos desenhos e pinturas do velho Rio - como os feitos por Ender, Henderson, Mary Graham, Debret e Rugendas. Sempre com meu excelente tio [...] (NAVA, 1974: 378-9).

Em Chão de ferro, Nava (1976: 80) retoma a descrição de "idas a Copacabana”, visitando "o Flamengo. A Ponte dos Presidentes. Botafogo com o Pavilhão de Regatas" e Jardim Botânico: "Meu tio Salles ministrava explicaçóes e eu ia incorporando os elementos de sua lembrança futura à orla marinha de nosso Rio". Amparada por nostálgica digressáo sobre os tios Alice e Salles, segue-se uma confidência ao leitor:

Quando o arquivo de Antônio Salles veio para minhas mãos lá descobri assentamentos de cuidados médicos dados a minha tia pelo dr. Lincoln de Araújo. Era terapêutica para esterilidade. Falhou. E digo-o com vergonhosa sensação de ciúme compensado - melhor para mim, melhor para o João. $\mathrm{O}$ almejado primo que não nasceu, acaso não desviaria de nós esse privilégio que foi o sentimento materno e paterno que ficamos devendo a esses queridos tios (NAVA, 1976: 77)?

O círio perfeito (1983) ilustra, igualmente, a atitude de preceptor adotada ante o sobrinho dileto: "O Nava aprendeu com outro homem humilde, seu tio Antônio Sales que era preciso ler tudo, até lista de telefone, até anúncios em bonde e jornal. Tudo é palavra, e a palavra, mesmo isolada, é nobre tal uma criatura” (NAVA, 1983: 473). Assim, nas memórias dos anos trinta e quarenta, o Nava adulto seria apresentado como:

O Egon, criado principalmente sob a influência da lembrança de seu pai, do exemplo de sua mãe e dos conselhos de seus tios Alice e Antônio Sales - que viviam no caminho difícil da virtude e que só eram capazes de dar a quem educavam a idéia errada e ingênua de que o mundo era paraíso e que todos os homens e mulheres eram homens e mulheres de bem (NAVA, 1983: 475).

Essa concepção "ingênua” do mundo evidencia-se no último episódio de Chão de ferro. Após deixar o Colégio Pedro II, Nava volta a morar com a mãe, Dona Diva Mariana Jaguaribe Nava, em Belo Horizonte, onde ingressa 
na faculdade de Medicina. As dificuldades eram tais que, a fim de "arcar com as despesas de um terno" para frequentar as aulas, a família vendeu ao sebo "Livraria e Papelaria de Belo Horizonte", quase cinquenta obras do acervo paterno, "uma coleçáo de teses de doutoramento escritas em Latim, as primeiras defendidas na Bahia e no Rio" (NAVA, 1976: 337), livros raros, como o Dictionnaire de Thérapeutique de Dujardin-Beaumetz e vários tratados de obstetrícia, ginecologia e farmacologia. Contudo, o alívio seria provisório:

Apesar dos esforços da minha Mãe tornou-se patente que, com as despesas de meus estudos, nossa situação estava ficando insustentável. Apresentou-se duramente o dilema: ou eu iria trabalhar deixando a Medicina ou arranjaria um emprego com folgas que me permitissem continuar na escola. Mas apelar para quem? [...] Foi entáo que escrevi a meu tio Antônio Sales. Carta minuciosa, absolutamente franca e me pondo inteiramente à disposição do conselho que ele me desse. Fiquei esperando a resposta. Naquele tempo, com o Lloyd, essas coisas demoravam mas, com um mês, chegava-me volumoso invólucro do tio do Ceará. Dizia que eu fazia tanto empenho em ser médico que seria imperdoável aconselhar outra carreira. Eu tinha razáo de procurar estudar trabalhando. Centenas tinham feito assim. Ele queria ajudar e mandava-me três cartas do seu amigo Justiniano de Serpa, então Presidente do Ceará, pedindo por mim ao seu colega de Minas - o Dr. Artur da Silva Bernardes e a dois dos seus Secretários (NAVA, 1976: 340-341).

Em agosto de 1921, as cartas de apresentação foram levadas pelo moço de dezoito anos, "primeiro, claro, ao Presidente do Estado [...] Estudava o que lhe havia de dizer. Tinha tanta certeza de seu abraço que já o amava por antecipaçáo" (NAVA, 1976: 341). Foi recebido somente por Afonso Pena Júnior, Secretário do estado de Minas Gerais. E, "pela maneira gentil de sua concessão", exerceria o cargo de "colaborador da Diretoria de Higiene com o ordenado de $120 \$ 000$ por mês" (NAVA, 1976: 346). Esse primeiro emprego foi decisivo para o prosseguimento e conclusão de seus estudos.

Salles faleceria em Fortaleza aos 72 anos, vítima de hipertensão arterial, a 14 de novembro de 1940. A correspondência entre Nava e sua tia Alice, iniciada em 30 de agosto de 1911, é registrada até 22 de setembro de 1961 (VASCONCELOS, 2001: 297). Na correspondência familiar de Salles, "a predominância é de cartas para Alice Nava Sales” (VASCONCELOS, 2007: 10), com destaque para as cartas de Nava. Em Baú de ossos, o memorialista conta o retorno, em 1959, ao Ceará, "para dar um curso na sua Universidade. Fui novamente ver a casa de minha avó. De todos os que eu vira ali em 1919, só estava viva minha tia Alice. [...] Tio Salles, morto" (NAVA, 1974: 45). No entanto, é na recordação do breve período que antecede seu ingresso no curso de Medicina que Nava deixa umas das mais impressivas descriçóes da influência de Salles: 
Nesses dias de chuva, preso em casa, comecei a organizar minha vida mineira [...] Arrumei num quarto que dava para o córrego a velha escrivaninha que fora de meu pai [...] Era para arrumar os livros de todo instante e o primeiro ali entronizado foi o dicionário médico de Littré. Sobre a mesa preguei com percevejos uma folha inteira de mata-borrão verde, dispus o tinteiro paterno e arrumei os lápis, borrachas, penas ao jeito que uso até hoje, que era o da mesa de tio Sales (NAVA, 1976: 277).

A memória permite a coexistência de diferentes dimensóes do tempo passado. Assim, adquirem simultaneidade, condensadas em uma única imagem, a história do médico José Pedro da Silva Nava, do erudito Antônio Salles, do Nava moço e anciáo. Os retratos conjugados de pai e tio, sugeridos por objetos impregnados de ambas as presenças, remetem às vocaçóes abraçadas por Nava, médico e escritor. A ideia de claustro na figura do jovem "preso em casa", disposto a organizar a vida que se inicia naquele momento, evoca o poeta bissexto, recluso, preparando-se, como o narrador machadiano, para "atar as duas pontas da vida, e restaurar na velhice a adolescência”. Realizando esse feito, Nava uniu à arte a faculdade ou habilidade de preservar imagens, intimamente relacionada aos ofícios do arquivista, biógrafo, historiador e memorialista.

\section{Referências bibliográficas}

ALBUQUERQUE, Claudia. Adolfo Caminha. Fortaleza: Ediçóes Demócrito Rocha, 2000.

ASSIS, Machado de. Esaú e Jacó. In: Obra Completa. Rio de Janeiro: Nova Aguilar, 1994. Disponível em: <http://machado.mec.gov.br/images/stories/pdf/romance/ marm09.pdf>. Acesso em: 11/04/2016.

AZEVEDO, Sânzio de. Lembrando o "tio Sales". In: Inventário do Arquivo Antônio Sales. Ministério da Cultura. Fundação Casa de Rui Barbosa. Arquivo-Museu de Literatura Brasileira. Rio de Janeiro: Ediçóes Casa de Rui Barbosa, 2007: 13-26. Disponível em: <http://www.casaruibarbosa.gov.br/dados/DOC/.../ Inventario_ArquivoAntonioSales.pdf>. Acesso em: 11/04/2016.

. Padeiros muito letrados. Fortaleza: Armazém da Cultura, 2015.

BARREIRA, Dolor. História da literatura cearense. Fortaleza: Instituto do Ceará, 1986.

BEZERRA, Carlos Eduardo de Oliveira. Adolfo Caminha: um polígrafo na literatura brasileira do século XIX (1885-1897). São Paulo: Editora da Unesp, 2009.

CAMINHA, Edmilson. Palavra de escritor. Brasília: Editora Thesaurus, 1995. 
COHEN, Paul A. History and Popular Memory: The Power of Story in Moments of Crisis. New York: Columbia University Press, 2014.

HOMANS, Peter. Symbolic Loss: the Ambiguity of Mourning and Memory at Century's End. Charlottesville and London: University Press of Virginia, 2000.

LE GOFF, Jacques. História e Memória. Campinas: Editora da Unicamp, 1996.

LÓPEZ, Fernando Durán. Estudio preliminar. In: QUINTANA, Manuel José. Memoria Del Cádiz de las Cortes. Cádiz: Universidad de Cádiz, 1996: 9-20.

MEETHAN, Kevin. Remaking Time and Space: The Internet, Digital Archives and Genealogy. In: GUELKE, Jeanne Kay; TIMOTHY, Dallen J. (Org.). Geography and Genealogy: Locating Personal Pasts. Hampshire/Burlington: Ashgate, 2008: 99-114.

NAVA, Pedro da Silva. Balão cativo. Rio de Janeiro: José Olympio Editora, 1973. . Baú de ossos. Rio de Janeiro: José Olympio Editora, 1974. . Chão de ferro. São Paulo: José Olympio Editora, 1976. . Galo das trevas. Rio de Janeiro: José Olympio Editora, 1981. . O círio perfeito. Rio de Janeiro: Nova Fronteira, 1983.

NICOLÁS, Elena González; GARCÍA, María Jesús Lavín. El archivo de San Román de Escalante. In: MARTÍNEZ, Rosa María Blasco. Patrimonio histórico. Santander: Universidad de Cantábria, 1994: 121-124.

SANTOS, Luiz Antonio de Castro. Poder, Ideologias e Saúde no Brasil da Primeira República: ensaio de sociologia histórica. In: HOCHMAN, Gilberto; ARMUS, Diego (Orgs.). Cuidar, controlar, curar: ensaios históricos sobre saúde e doença na América Latina e Caribe. Rio de Janeiro: Editora Fiocruz, 2004: 249-294.

TARCUS, Horacio. Archivos, bibliotecas y la memoria obrera, social y cultural de los argentinos. In: AGUIRRE, Carlos; VILLA-FLORES, Javier (Eds.). From the Ashes of History: Loss and Recovery of Archives and Libraries in Modern Latin America. Raleigh: Editoria A Contracorriente, 2015: 305-338.

VASCONCELLOS, Eliane (Org.). Inventário do Arquivo Antônio Sales. Ministério da Cultura. Fundação Casa de Rui Barbosa. Arquivo-Museu de Literatura Brasileira. Rio de Janeiro: Ediçóes Casa de Rui Barbosa, 2007. Disponível em: <http:// www.casaruibarbosa.gov.br/dados/DOC/.../Inventario_ArquivoAntonioSales. pdf>. Acesso em: 11/04/2016.

- Inventário do Arquivo Pedro Nava. Ministério da Cultura. Fundação Casa de Rui Barbosa. Arquivo-Museu de Literatura Brasileira. Rio de Janeiro: Ediçóes Casa de Rui Barbosa, 2001. Disponível em: <http://www.casaruibarbosa.gov.br/ pedronava/downloads/inventarionava.pdf>. Acesso em: 11/04/2016. 
Maria Alice Ribeiro Gabriel. Possui graduação em Letras pela Universidade Federal de Uberlândia (1998), mestrado em Estudos Literários pela Universidade Estadual Paulista Júlio de Mesquita Filho (2003) e doutorado em História Social pela Universidade de São Paulo (2011). Tem experiência na área de Letras, com ênfase em Literatura Brasileira.

E-mail: rgabriel1935@gmail.com

Recebido em: 16/09/2016

Aprovado em: 15/03/2017 